\title{
Treatment outcomes of patients with chronic hepatitis $C$ receiving sofosbuvir- based combination therapy within national hepatitis $C$ elimination program in the country of Georgia
}

Tengiz Tsertsvadze ${ }^{1,2^{*}}$, Amiran Gamkrelidze ${ }^{3}$, Muazzam Nasrullah4 ${ }^{4}$ Lali Sharvadze ${ }^{1,2,5}$, Juliette Morgan ${ }^{4}$, Shaun Shadaker ${ }^{4}$, Lia Gvinjilia ${ }^{6}$, Maia Butsashvili', David Metreveli ${ }^{8}$, Vakhtang Kerashvili', Marina Ezugbaia', Nikoloz Chkhartishvili ${ }^{1}$, Akaki Abutidze', Valeri Kvaratskhelia ${ }^{9}$ and Francisco Averhoff ${ }^{4}$

\begin{abstract}
Background: Georgia has one of the highest HCV prevalence in the world and launched the world's first national HCV elimination programs in 2015. Georgia set the ambitious target of diagnosing $90 \%$ of people living with HCV, treating $95 \%$ of those diagnosed and curing $95 \%$ of treated patients by 2020 . We report outcomes of Sofosbuvir (SOF) based treatment regimens in patients with chronic HCV infection in Georgia.
\end{abstract}

Methods: Patients with cirrhosis, advanced liver fibrosis and severe extrahepatic manifestations were enrolled in the treatment program. Initial treatment consisted of SOF plus ribavirin (RBV) with or without pegylated interferon (INF). Sustained virologic response (SVR) was defined as undetectable HCV RNA at least 12 weeks after the end of treatment. SVR were calculated using both per-protocol and modified intent-to-treat (mITT) analysis. Results for patients who completed treatment through 31 October 2018 were analyzed.

Results: Of the 7342 patients who initiated treatment with SOF-based regimens, 5079 patients were tested for SVR. Total SVR rate was $82.1 \%$ in per-protocol analysis and $74.5 \%$ in $\mathrm{mITT}$ analysis. The lowest response rate was observed among genotype 1 patients (69.5\%), intermediate response rate was achieved in genotype 2 patients (81.4\%), while the highest response rate was among genotype 3 patients (91.8\%). Overall, SOF/RBV regimens achieved lower response rates than IFN/SOF/RBV regimen $(72.1 \%$ vs $91.3 \%, P<0.0001)$.

In multivariate analysis being infected with HCV genotype $2(\mathrm{RR}=1.10, \mathrm{Cl}[1.05-1.15])$ and genotype $3(\mathrm{RR}=1.14, \mathrm{Cl}$ [1.11-1.18]) were associated with higher SVR. Patients with cirrhosis ( $R R=0.95, \mathrm{Cl}[0.93-0.98]$ ), receiving treatment regimens of SOF/RBV 12 weeks, SOF/RBV 20 weeks, SOF/RBV 24 weeks and SOF/RBV 48 weeks (RR $=0.85, \mathrm{Cl}[0.81-0.91]$; $\mathrm{RR}=0.86, \mathrm{Cl}[0.82-0.92] ; \mathrm{RR}=0.88, \mathrm{Cl}[0.85-0.91]$ and $\mathrm{RR}=0.92$, Cl [0.87-0.98], respectively) were less likely to achieve SVR.

Conclusions: Georgia's real world experience resulted in high overall response rates given that most patients had severe liver damage. Our results provide clear evidence that SOF plus IFN and RBV for 12 weeks can be considered a treatment option for eligible patients with all three HCV genotypes. With introduction of next generation DAAs, significantly improved response rates are expected, paving the way for Georgia to achieve HCV elimination goals.

Keywords: HCV, Elimination, DAAs, SVR, Georgia

\footnotetext{
* Correspondence: tt@aidscenter.ge

${ }^{1}$ Infectious Diseases, AIDS and Clinical Immunology Research Center, Tbilisi, Georgia

${ }^{2}$ Ivane Javakhishvili Tbilisi State University, Faculty of Medicine, Tbilisi, Georgia Full list of author information is available at the end of the article
}

(c) The Author(s). 2020 Open Access This article is distributed under the terms of the Creative Commons Attribution 4.0 International License (http://creativecommons.org/licenses/by/4.0/), which permits unrestricted use, distribution, and reproduction in any medium, provided you give appropriate credit to the original author(s) and the source, provide a link to the Creative Commons license, and indicate if changes were made. The Creative Commons Public Domain Dedication waiver (http://creativecommons.org/publicdomain/zero/1.0/) applies to the data made available in this article, unless otherwise stated. 


\section{Background}

Globally, an estimated 71 million people are chronically infected with hepatitis C virus (HCV), and 400, 000 die annually from hepatitis C-related liver diseases [1]. Management of HCV infection has been revolutionized after the availability of direct acting antivirals (DAAs), and Sofosbuvir (SOF) was the first widely introduced DAA [2, 3]. Clinical trials have demonstrated high efficacy of SOF-based regimens in patients infected with genotypes 1-6 [4-8].

Georgia has one of the highest $\mathrm{HCV}$ prevalence rates among general population in the world [9], and launched the world's first national HCV elimination program in 2015 [10]. The elimination program has adopted a comprehensive strategy that addresses both prevention and treatment of $\mathrm{HCV}$ infection. A key component of the program is the provision of DAAs free of charge to all Georgian citizens; this was made possible through an agreement with Gilead Sciences to donate DAAs. Georgia has set itself the ambitious target of diagnosing 90\% (135,000 persons) of people living with $\mathrm{HCV}$, treating 95\% (128,000 persons) of those diagnosed and curing 95\% (121000) of treated patients by 2020 [9]. We report outcomes of SOFbased treatment regimens in patients with chronic $\mathrm{HCV}$ infection in the country of Georgia.

\section{Methods}

All Georgians aged 18 years or older that are infected with $\mathrm{HCV}$ are eligible for the free of charge treatment program. The hepatitis $\mathrm{C}$ elimination program was launched on 28 April 2015. All patients treated from launch through 31 October 2018 are included in the analysis. Treatment-naive and experienced patients with cirrhosis (including decompensated cirrhosis), advanced liver fibrosis, severe extrahepatic manifestations, HCV re-infection after liver transplantation and HIV-coinfection were prioritized for enrollment in the treatment program. Initially, DAA treatment was exclusively SOF based and included ribavirin (RBV) with or without pegylated interferon, depending on the $\mathrm{HCV}$ genotype, per national guidelines. From February 2016, more effective, interferon free DAA combination - sofosbuvir and ledipasvir (SOF/LDV) was introduced, and treatment regimens were revised. Beginning in June 2016, treatment criteria were relaxed allowing enrollment of all $\mathrm{HCV}$ infected persons regardless of level of liver fibrosis, to be treated. Treatment guidelines were established by a committee composed of treatment experts from Georgia in consultation with international experts. Based on eligibility of interferon therapy all HCV genotype 1 and 3 patients received SOF plus, Pegylated interferon (IFN) and RBV for 12 weeks or SOF plus RBV for 24 weeks.
HCV genotype 2 treatment naïve patients without cirrhosis were treated with the 12-week combination of SOF plus RBV, while cirrhotic patients and those with prior treatment failure received the 12-week regimen of SOF plus IFN and RBV or the 20-week regimen of SOF plus RBV based on eligibility of interferon. Patients with decompensated cirrhosis received SOF plus RBV for 48 weeks.

Treatment was initially limited to four sites in Tbilisi, and later expanded with sites from other cities within Georgia; by October 2018, 31 sites were providing $\mathrm{HCV}$ treatment in the country. The $\mathrm{HCV}$ treatment program providers also participated in Project ECHO (Extension for Community Healthcare Outcomes).

A national HCV treatment database was established, which collected standard data for each patient enrolled in treatment program. Each treatment site was responsible for data entry for each enrolled patient. Data were de-identified and sociodemographic, clinical and laboratory data were extracted from national HCV treatment database. Characteristics measured included: age, gender, HCV RNA, FIB-4 test score, METAVIR score, HBsAg, treatment regimen, HCV genotype and city where treatment was provided. Sustained virologic response (SVR) was defined as undetectable HCV RNA at least 12 weeks after the end of treatment. The presence of cirrhosis was confirmed by vibration-controlled transient elastography or acoustic radiation force impulse elastography (ARFI) compatible with stage F4 fibrosis ( $\geq 14.5 \mathrm{kpa}$ )_by METAVIR. Decompensated cirrhosis was defined as the presence of current or past ascites, hepatic encephalopathy and variceal haemorrhage etc. SVRs were calculated using both per-protocol and modified intent-to-treat (mITT) analysis. Per-protocol approach included only those with complete SVR data, while in mITT analysis persons discontinuing treatment were also included. Persons who died or had no SVR test $>24$ weeks after completing treatment were excluded from analysis.

\section{Statistical analysis}

All analyses were performed with SAS version 9.3 software (SAS Institute, Inc., Cary, NC, USA). Variables were categorized as follows: age category: 18-44, 45-60, and > 60; HCV RNA category: < 800,000 IU/mL vs. $\geq 800$, $000 \mathrm{IU} / \mathrm{mL}$; FIB-4 test: <1.45, $1.45-3.25$ and $>3.25$; METAVIR score: $<$ F4 and F4. We used the chi-square or Fisher's exact to compare differences in categorical variables with SVR. We performed a multivariate logistic-regression analysis involving baseline demographic, clinical and laboratory characteristics to identify independent predictors of SVR. A $p$-value $<0.05$ was considered significant. The final model included 
variables associated $(p<0.05)$ with SVR in the bivariate analysis. The results are presented with a Risk ratio (RR) and 95\% Confidence intervals (CIs). Results for patients who completed treatment and tested for SVR through 31 October 2018 were analyzed. The study was approved by the Institutional review board of the Infectious Diseases, AIDS and Clinical Immunology Research Center, Tbilisi.

\section{Results}

A total of 7342 patients with chronic HCV infection received SOF-based therapy from April 28, 2015 until October 31, 2018 and 5079 had complete SVR data.

The pretreatment demographics, clinical and laboratory characteristics of patients with complete SVR data are described in Table 1. Most patients, 2838 (55.9\%) were age 45-60 years, 4381 (86.3\%) were males and 2783 (57.9\%) had stage F4 fibrosis (by METAVIR). Overall, 1724 (33.9\%) of the patients had HCV genotype 1, followed by $\mathrm{HCV}$ genotype 3, 2305 (45.4\%) and $\mathrm{HCV}$ genotype 2, 1047 (20.6\%). Only 3 patients were infected with $\mathrm{HCV}$ genotype 4. Majority of patients were treated with IFN/SOF/RBV for 12 weeks (52.1\%), followed by SOF/RBV for 24 weeks (27.9\%), SOF/RBV for 20 weeks (7.8\%), SOF/RBV for 12 weeks (7.2\%), and SOF/RBV for 48 weeks (5.0\%).

A total of 521 persons discontinued treatment, with the most common causes for not completing treatment being death $(48.8 \% ; n=254)$, self-discontinuation $(19.6 \% ; n=$ 102), and loss to follow up (15.9\%; $n=83)$. Among those who died during treatment, the majority 299/521 (57.4\%) had severe liver disease (METAVIR scores of F3 or F4).

A total of 5079 persons with complete SVR data and 521 persons who discontinued treatment, were included in treatment efficacy analysis (total 5600 persons). Total SVR rate was $82.1 \%(4170 / 5079)$ in per-protocol analysis and $74.5 \%(4170 / 5600)$ in mITT analysis.

Of those with an SVR12, the lowest response rate was observed among genotype 1 patients (1198/1724; $69.5 \%$ ), intermediate response rate was achieved in genotype 2 patients $(852 / 1047 ; 81.4 \%)$, while the highest response rate was among genotype 3 patients $(2117 / 2305$; 91.8\%). There were only 3 patients with genotype 4 and all were cured.

Overall, SOF/RBV regimens achieved lower response rates than IFN/SOF/RBV regimen $(72.1 \%$ vs $91.3 \%, P<$ $0.0001)$. This difference was seen in all genotypes $(57.0 \%$ vs $80.8 \%, P<0.0001$ for genotype $1 ; 76.9 \%$ vs $96.3 \%, P<$ 0.0001 for genotype 2 and $82.5 \%$ vs $96.9 \%, P<0.0001$ for genotype 3 respectively) (Fig. 1).

Multivariate analysis (Table 2) showed that when controlling those factors which were significantly associated with SVR in bivariate analysis, being infected with $\mathrm{HCV}$ genotype 2 (RR $=1.10, \mathrm{CI}[1.05-1.15], P=0.001)$ and genotype $3(\mathrm{RR}=1.14$, CI [1.11-1.18], $P<0.0001)$ were associated with higher SVR. Patients with cirrhosis $(\mathrm{RR}=$ 0.95, CI [0.93-0.98], $P<0.0001)$, receiving treatment regimens of SOF/RBV 12 weeks, SOF/RBV 20 weeks, $\mathrm{SOF} / \mathrm{RBV} 24$ weeks and SOF/RBV 48 weeks $(\mathrm{RR}=0.85$, CI [0.81-0.91], $P<0.0001 ; \mathrm{RR}=0.86$, CI [0.82-0.92], $P<0.0001 ; \mathrm{RR}=0.88$, CI [0.85-0.91], $P<0.0001$ and $\mathrm{RR}=0.92$, CI [0.87-0.98], $P=0.005$, respectively) were less likely to achieve SVR.

\section{Discussion}

This study from Georgia is one of the largest realworld cohorts examining outcomes of $\mathrm{HCV}$ treatment with SOF based regimens, among patients with severe liver disease. We assessed real-world efficacy of SOF plus RBV with or without IFN in these difficult-to-treat patients with chronic hepatitis C. Our study demonstrated that SOF-based regimens can result in high overall SVR rates, similar to SVR rates achieved in clinical trials [11, 12]. While newer combination DAAs are now available, SOF is now one of the most readily available DAAs worldwide, at affordable prices in many low middle income countries, and as such, these findings have relevance today. In particular, the acceptable SOF plus RBV outcomes among the most severely ill patients, regardless of genotype are highly relevant.

In our study response rates among patients with $\mathrm{HCV}$ genotype 2 were lower than reported in clinical trials and real-life studies which showed high efficacy of SOF plus RBV combination treatment among HCV genotype 2 patients including those with cirrhosis and/or treatment experience [8, 12-15]. Lower efficacy of treatment in genotype 2 patients may have been associated with a reported high prevalence of $\mathrm{HCV}$ recombinant form $2 \mathrm{k} / 1 \mathrm{~b}$ among Georgian $\mathrm{HCV}$ genotype 2 patients [16]; these patients do not respond well to standard treatment for genotype 2 and regimens used for genotype 1 seem to be more effective [17]. Therefore there is a need for reassessing existing modalities for the management of HCV genotype 2 infection, especially in areas with high prevalence of $\mathrm{HCV}$ recombinant form $2 \mathrm{k} / 1 \mathrm{~b}$ [18].

We observed high cure rates in HCV genotype 3 patients that are one of the most challenging subpopulations to treat [19]. IFN-based regimens were superior to SOF/RBV alone. The results of clinical trials showed that HCV genotype 3 patients achieved higher SVR12 rates with a 12 week SOF and RBV in combination with IFN that patients who were treated with SOF and RBV alone [12].

Our findings support use of a 12 week regimen of SOF plus RBV in combination with IFN as a treatment option for eligible $\mathrm{HCV}$ genotype 3 patients in settings, where 
Table 1 Baseline characteristics of adult persons with complete SVR data treated with SOF-based regimens by HCV genotypes within the national hepatitis C elimination program, April 28, 2015 - October 31, 2018

\begin{tabular}{|c|c|c|c|c|c|c|c|c|c|c|}
\hline \multirow[t]{2}{*}{ Characteristic } & \multicolumn{2}{|c|}{ TOTAL } & \multicolumn{2}{|c|}{ Genotype 1} & \multicolumn{2}{|c|}{ Genotype 2} & \multicolumn{2}{|c|}{ Genotype 3} & \multicolumn{2}{|c|}{ Genotype 4} \\
\hline & $n$ & $\%$ & $n$ & $\%$ & $n$ & $\%$ & $n$ & $\%$ & $\mathrm{n}$ & $\%$ \\
\hline \multicolumn{11}{|l|}{ Age category, n (\%) } \\
\hline $18-45$ & 1635 & 32.2 & 386 & 22.4 & 299 & 28.6 & 948 & 41.1 & 2 & 66.7 \\
\hline $45-60$ & 2838 & 55.9 & 944 & 54.8 & 630 & 60.2 & 1264 & 54.8 & & . \\
\hline $60+$ & 606 & 11.9 & 394 & 22.9 & 118 & 11.3 & 93 & 4.0 & 1 & 33.3 \\
\hline \multicolumn{11}{|l|}{ Gender, n (\%) } \\
\hline Female & 698 & 13.7 & 486 & 28.2 & 101 & 9.6 & 110 & 4.8 & 1 & 33.3 \\
\hline Male & 4381 & 86.3 & 1238 & 71.8 & 946 & 90.4 & 2195 & 95.2 & 2 & 66.7 \\
\hline \multicolumn{11}{|c|}{ HCV RNA categories, n (\%) } \\
\hline$<800,000 \mathrm{IU} / \mathrm{mL}$ & 2922 & 57.7 & 901 & 52.5 & 625 & 59.8 & 1393 & 60.5 & 3 & 100.0 \\
\hline$\geq 800,000 \mathrm{IU} / \mathrm{mL}$ & 2145 & 42.3 & 816 & 47.5 & 420 & 40.2 & 909 & 39.5 & & . \\
\hline \multicolumn{11}{|l|}{ FIB-4 Test } \\
\hline$<1.45$ & 200 & 5.7 & 65 & 6.0 & 51 & 7.0 & 84 & 5.0 & & . \\
\hline $1.45-3.25$ & 1763 & 50.2 & 491 & 45.0 & 403 & 55.1 & 868 & 51.5 & 1 & 50.0 \\
\hline$>3.25$ & 1546 & 44.1 & 535 & 49.0 & 277 & 37.9 & 733 & 43.5 & 1 & 50.0 \\
\hline \multicolumn{11}{|l|}{ Metavir score } \\
\hline$<\mathrm{F} 4$ & 2021 & 42.1 & 676 & 39.8 & 516 & 50.9 & 827 & 39.6 & 2 & 66.7 \\
\hline F4 & 2783 & 57.9 & 1021 & 60.2 & 497 & 49.1 & 1264 & 60.4 & 1 & 33.3 \\
\hline \multicolumn{11}{|l|}{ Liver function tests, n (\%) } \\
\hline $\mathrm{ALT}>2 \times \mathrm{ULN}$ & 2585 & 51.0 & 731 & 42.5 & 466 & 44.6 & 1385 & 60.2 & 3 & 100.0 \\
\hline AST $>2 \times$ ULN & 2604 & 51.4 & 783 & 45.6 & 442 & 42.3 & 1376 & 59.8 & 3 & 100.0 \\
\hline Billirubin $>1.1 \mathrm{mg} / \mathrm{dL}$ & 4423 & 87.3 & 1520 & 88.5 & 928 & 88.8 & 1972 & 85.7 & 3 & 100.0 \\
\hline Albumin $<35 \mathrm{~g} / \mathrm{L}$ & 2001 & 39.5 & 670 & 39.0 & 469 & 44.9 & 862 & 37.4 & . & \\
\hline INR $>1.49$ & 687 & 13.6 & 260 & 15.1 & 132 & 12.6 & 295 & 12.8 & & . \\
\hline \multicolumn{11}{|l|}{ Co-infections, n (\%) } \\
\hline $\mathrm{HBsAg}+$ & 108 & 2.2 & 28 & 1.7 & 19 & 1.9 & 61 & 2.8 & & . \\
\hline $\mathrm{HBsAg-}$ & 4777 & 97.8 & 1666 & 98.3 & 985 & 98.1 & 2123 & 97.2 & 3 & 100.0 \\
\hline \multicolumn{11}{|l|}{ Treatment regimen, $\mathrm{n}(\%)$} \\
\hline IFN/SOF/RBV (12 wk) & 2646 & 52.1 & 905 & 52.5 & 240 & 22.9 & 1500 & 65.1 & 1 & 33.3 \\
\hline SOF/RBV (12 wk) & 364 & 7.2 & 3 & 0.2 & 360 & 34.4 & 1 & 0 & & . \\
\hline SOF/RBV (20 wk) & 395 & 7.8 & 3 & 0.2 & 392 & 37.4 & & & & . \\
\hline SOF/RBV (24 wk) & 1418 & 27.9 & 695 & 40.3 & 7 & 0.7 & 714 & 31 & 2 & 66.7 \\
\hline SOF/RBV (48 wk) & 256 & 5 & 118 & 6.8 & 48 & 4.6 & 90 & 3.9 & . & \\
\hline \multicolumn{11}{|c|}{ City of treatment site, n (\%) } \\
\hline Tbilisi & 3800 & 74.8 & 1294 & 75.1 & 819 & 78.2 & 1684 & 73.1 & 3 & 100 \\
\hline Kutaisi & 362 & 7.1 & 148 & 8.6 & 72 & 6.9 & 142 & 6.2 & & . \\
\hline Batumi & 501 & 9.9 & 177 & 10.3 & 67 & 6.4 & 257 & 11.1 & . & \\
\hline Zugdidi & 328 & 6.5 & 90 & 5.2 & 81 & 7.7 & 157 & 6.8 & & . \\
\hline Gori & 42 & 0.8 & 6 & 0.3 & 5 & 0.5 & 31 & 1.3 & . & . \\
\hline Rustavi & 40 & 0.8 & 9 & 0.5 & 3 & 0.3 & 28 & 1.2 & & . \\
\hline Lanchkhuti & 4 & 0.1 & . & . & . & . & 4 & 0.2 & . & . \\
\hline Gurjaani & 2 & 0 & . & . & . & . & 2 & 0.1 & . & . \\
\hline
\end{tabular}




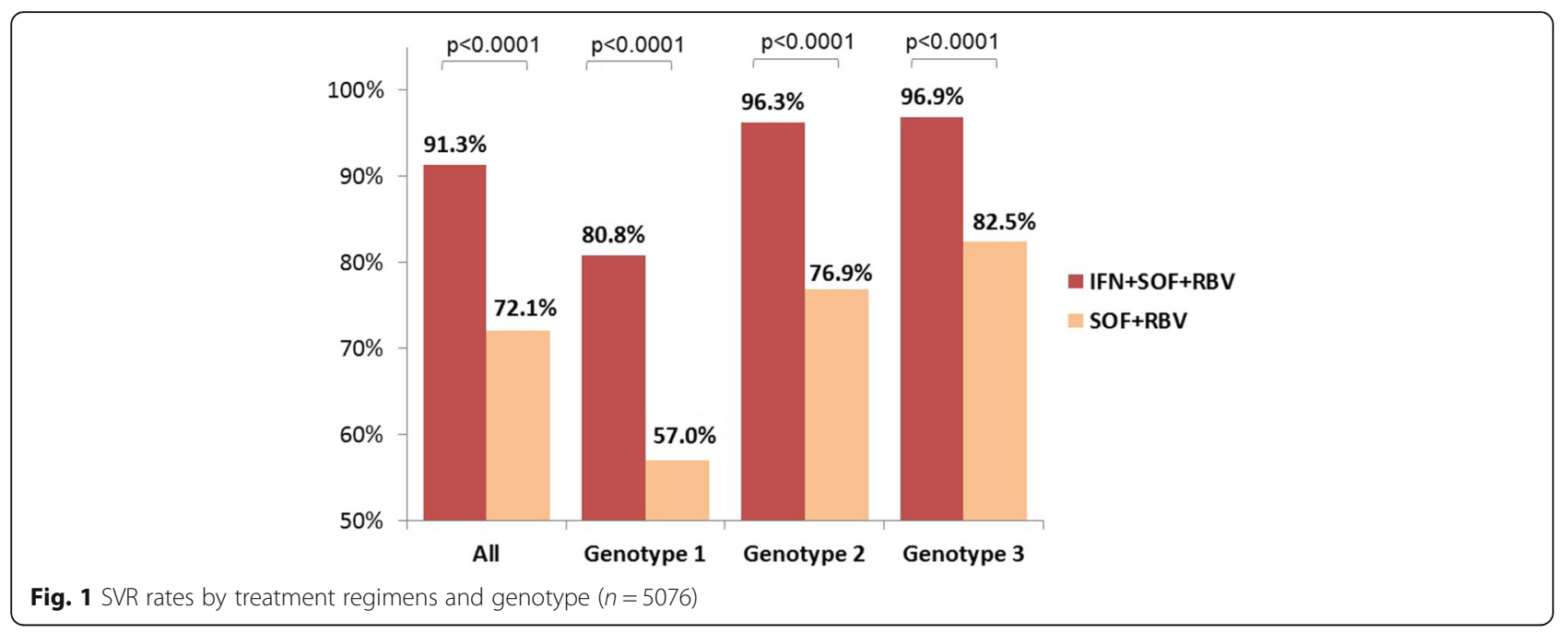

new highly potent and well-tolerated DAAs against genotypes 2 and 3 are not available. Our results suggest the use of SOF/RBV combination for 24 weeks as an option for patients who cannot tolerate IFN.

After examining host and viral factors we found that presence of cirrhosis, and receiving IFN-free regimens were associated with lower SVR in a multivariable model. The low rates of response among cirrhotic patients is consistent with previous studies.

One strength of this study is the large number of patients as well as standardized treatment guidelines and standardized data collection. The diversity of our cohort with respect to sex, age, and genotype distribution makes our findings generalizable, reflecting reported real-world outcomes. Our study has several limitations. First, data from patients in whom prior treatment had failed, was not collected. Second, liver fibrosis was assessed by multiple noninvasive indices, each of which have limitations on accuracy [20-22]. The national treatment database, which captures information on all hepatitis $C$ patients enrolled in the program, provides accurate treatment related information on a national level. However it does not contain detailed information on some variables, including comorbidities (diabetes mellitus, kidney failure, extrahepatic manifestations etc.) as well as nature of deaths, adverse events and reasons of self-discontinuation. Also data available in the national system has limited ability to answer questions as to why people are lost to follow-up along the continuum of care. Significant number of patients who were lost to follow-up after treatment completion is a serious challenge of the treatment program. However, in 2017 the program offered SVR assessment free of charge that would lead to reducing missing SVR data.. Despite notable progress of the Georgia HCV elimination program, challenges to Georgia achieving the national targets for HCV elimination by 2020 remain. Pangenotypic DAAs that are effective across the different genotypes of HCV introduced in late 2018 could have a substantial impact on improving access and simplifying diagnosis and treatment.

\section{Conclusion}

In conclusion, in this large cohort study, a combination of SOF and weight-based RBV with or without IFN appeared to be an effective regimen to treat chronic HCV-infected patients, especially for $\mathrm{HCV}$ Genotype 2 and 3 patients. SOF formed the foundation of the $\mathrm{HCV}$ elimination program in Georgia. Cure rates in patients without cirrhosis were high, which are comparable with those reported in clinical trials. However, consistent with previous studies, the presence of liver cirrhosis were associated with lower SVR12 rates. Our results provide clear evidence that SOF plus IFN and RBV for 12 weeks can be considered a treatment option for eligible patients with all three HCV genotypes. With the introduction of next generation DAAs, replacement of IFN-based regimens by IFN-free regimens and significantly improved response rates are expected, paving the way for Georgia to achieve the goal of $\mathrm{HCV}$ elimination. High cure rates obtained with SOF/LDV combinations for all HCV genotypes within Georgia program highlights effectiveness of service delivery model, which is based on simplified modalities that can be successfully replicated in non-specialty settings, which is important in light of ongoing decentralization process. Strong governmental commitment coupled with effective local and international partnerships provide a basis for turning the ambitious goal of elimination into reality. 
Table 2 Treatment outcomes and associated factors among adult persons with complete SVR data receiving SOF-based regimens within the national hepatitis C elimination program, April 28, 2015 - October 31, 2018

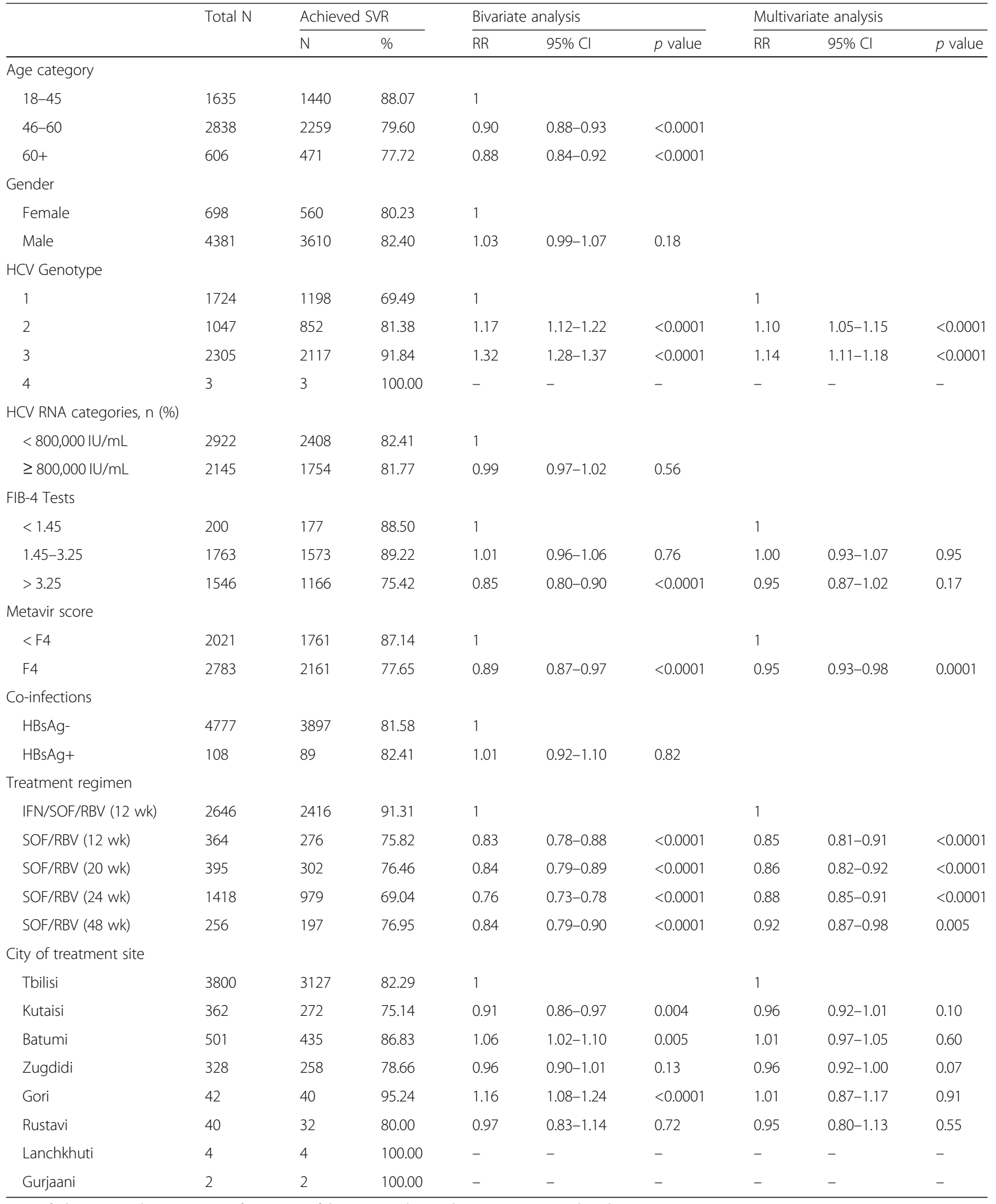

SOF Sofosbuvir, RBV Ribavirin, IFN Interferon, CI Confidence interval, RR Risk ratio, SVR Sustained virologic response 


\section{Abbreviations}

Cl: Confidence intervals; DAAs: Direct acting antivirals; HCV: Hepatitis C virus; INF: Pegylated interferon; mITT: modified intent-to-treat; RBV: Ribavirin; RR: Risk ratio; SOF: Sofosbuvir; SVR: Sustained virologic response

\section{Acknowledgements}

Authors gratefully acknowledge Gilead Science for donating Sofosbuvir and Ledipasvir/Sofosbuvir to the national hepatitis C elimination program at no cost.

\section{Authors' contributions}

Concept and design (TT, AG, FA, NC, AA), statistical analyses (SS, NC, AA), interpretation of the data (TT, AG, MN, LS, JM, SS, LG, MB, DM, VK, ME, NC, $A A, V K, F A)$, drafting the manuscript (TT) and critical revision of the manuscript for intellectual content (TT, AG, MN, LS, JM, SS, LG, MB, DM, VK $M E, N C, A A, V K, F A)$. All authors read and approve the final manuscript.

\section{Funding}

No funding was obtained for this study.

\section{Availability of data and materials}

The data that support the findings of this study are property of Georgia's HCV elimination program. In case the data is requested, please contact scientific committee of Georgia's HCV elimination program (Secretary Dr. Tinatin Kuchuloria, email: drkuchuloria@yahoo.com).

\section{Ethics approval and consent to participate}

The study was approved by the Institutional review board of the Infectious Diseases, AIDS and Clinical Immunology Research Center, Tbilisi.

\section{Consent for publication}

Not Applicable.

\section{Competing interests}

The authors declare that they have no competing interests.

\section{Author details}

${ }^{1}$ Infectious Diseases, AIDS and Clinical Immunology Research Center, Tbilisi, Georgia. ${ }^{2}$ Ivane Javakhishvili Tbilisi State University, Faculty of Medicine, Tbilisi, Georgia. ${ }^{3}$ National Center for Disease control and public health, 99, Kakheti highway, 0198 Tbilisi, Georgia. ${ }^{4}$ Emerging Infections Program, Centers for Disease Control and Prevention (CDC), Division of Viral Hepatitis National Center for HIV, Hepatitis, STD\&TB Prevention, Atlanta, USA. ${ }^{5}$ Hepatology Clinic HEPA, Tbilisi, Georgia. ${ }^{6}$ CDC Foundation, Georgia Hepatitis C Elimination Program, Tbilisi, Georgia. ${ }^{7}$ Clinic NeoLab, Tbilisi, Georgia. ${ }^{8}$ Medical Center Mrcheveli, Tbilisi, Georgia. ${ }^{9}$ Ministry of Labor, Health and Social Affairs of Georgia, Tbilisi, Georgia.

Received: 17 April 2019 Accepted: 27 December 2019

Published online: 10 January 2020

\section{References}

1. WHO Hepatitis C fact sheet. Updated April 2017. http://www.who.int/ mediacentre/factsheets/fs164/en/. .

2. Gane EJ, Stedman CA, Hyland RH, et al. Nucleotide polymerase inhibitor sofosbuvir plus ribavirin for hepatitis C. N Engl J Med. 2013; 368(1):34-44

3. Gentile I, Maraolo AE, Buonomo AR, Zappulo E, Borgia G. The discovery of sofosbuvir: a revolution for therapy of chronic hepatitis C. Expert Opin Drug Discovery. 2015;10(12):1363-77.

4. Rodriguez-Torres M, Lawitz E, Kowdley KV, et al. Sofosbuvir (GS-7977) plus peginterferon/ribavirin in treatment-naive patients with HCV genotype 1: a randomized, 28-day, dose-ranging trial. J Hepatol. 2013;58(4):663-8.

5. Kowdley KV, Lawitz E, Crespo I, et al. Sofosbuvir with pegylated interferon alfa-2a and ribavirin for treatment-naive patients with hepatitis $C$ genotype1 infection (ATOMIC): an open-label, randomised, multicentre phase 2 trial. Lancet. 2013;381(9883):2100-7.

6. Lawitz E, Lalezari JP, Hassanein T, et al. Sofosbuvir in combination with peginterferon alfa-2a and ribavirin for non-cirrhotic, treatment-naive patients with genotypes 1,2 , and 3 hepatitis $C$ infection: a randomised, double-blind, phase 2 trial. Lancet Infect Dis. 2013;13(5):401-8.
7. Lawitz E, Poordad FF, Pang PS, et al. Sofosbuvir and ledipasvir fixed-dose combination with and without ribavirin in treatment-naive and previously treated patients with genotype 1 hepatitis C virus infection (LONESTAR): an open-label, randomised, phase 2 trial. Lancet. 2014;383(9916):515-23.

8. Zeuzem S, Dusheiko GM, Salupere R, et al. Sofosbuvir and ribavirin in HCV genotypes 2 and 3. N Engl J Med. 2014;370(21):1993-2001.

9. Mitruka K, Tsertsvadze T, Butsashvili M, et al. Launch of a Nationwide Hepatitis C Elimination Program--Georgia, April 2015. MMWR Morb Mortal Wkly Rep. 2015;64(28):753-7.

10. Nasrullah M, Sergeenko D, Gvinjilia L, et al. The Role of Screening and Treatment in National Progress Toward Hepatitis C Elimination - Georgia, 2015-2016. MMWR Morb Mortal Wkly Rep. 2017;66(29):773-6.

11. Stedman C. Sofosbuvir, a NS5B polymerase inhibitor in the treatment of hepatitis C: a review of its clinical potential. Ther Adv Gastroenterol. 2014; 7(3):131-40.

12. Foster GR, Pianko S, Brown A, et al. Efficacy of sofosbuvir plus ribavirin with or without peginterferon-alfa in patients with hepatitis $C$ virus genotype 3 infection and treatment-experienced patients with cirrhosis and hepatitis C virus genotype 2 infection. Gastroenterology. 2015;149(6):1462-70.

13. Lawitz E, Gane EJ. Sofosbuvir for previously untreated chronic hepatitis C infection. N Engl J Med. 2013;369(7):678-9.

14. Jacobson IM, Gordon SC, Kowdley KV, et al. Sofosbuvir for hepatitis C genotype 2 or 3 in patients without treatment options. N Engl J Med. 2013; 368(20):1867-77.

15. Welzel TM, Nelson DR, Morelli G, et al. Effectiveness and safety of sofosbuvir plus ribavirin for the treatment of HCV genotype 2 infection: results of the real-world, clinical practice HCV-TARGET study. Gut. 2016;66:1844.

16. Karchava M, Waldenstrom J, Parker $M$, et al. High incidence of the hepatitis $C$ virus recombinant $2 \mathrm{k} / 1 \mathrm{~b}$ in Georgia: recommendations for testing and treatment. Hepatol Res. 2015;45(13):1292-8.

17. Hedskog C, Doehle B, Chodavarapu K, et al. Characterization of hepatitis C virus intergenotypic recombinant strains and associated virological response to sofosbuvir/ribavirin. Hepatology. 2015:61(2):471-80.

18. Karchava M, Chkhartishvili N, Sharvadze $L$, et al. Impact of hepatitis C virus recombinant form RF1 2k/1b on treatment outcomes within the Georgian national hepatitis C elimination program. Hepatol Res. 2017;48(1):36.

19. Tapper EB, Afdhal NH. Is 3 the new 1: perspectives on virology, natural history and treatment for hepatitis C genotype 3. J Viral Hepat. 2013;20(10): 669-77.

20. Lawitz E, Sulkowski MS, Ghalib R, et al. Simeprevir plus sofosbuvir, with or without ribavirin, to treat chronic infection with hepatitis $C$ virus genotype 1 in non-responders to pegylated interferon and ribavirin and treatmentnaive patients: the COSMOS randomised study. Lancet. 2014;384(9956): 1756-65.

21. Bonder A, Tapper EB, Afdhal NH. Contemporary assessment of hepatic fibrosis. Clin Liver Dis. 2015:19(1):123-34.

22. Tapper EB, Bacon BR, Curry MP, et al. Real-world effectiveness for 12 weeks of ledipasvir-sofosbuvir for genotype 1 hepatitis C: the trio health study. J Viral Hepat. Jan 2017;24(1):22-7.

\section{Publisher's Note}

Springer Nature remains neutral with regard to jurisdictional claims in published maps and institutional affiliations.

Ready to submit your research? Choose BMC and benefit from

- fast, convenient online submission

- thorough peer review by experienced researchers in your field

- rapid publication on acceptance

- support for research data, including large and complex data types

- gold Open Access which fosters wider collaboration and increased citations

- maximum visibility for your research: over $100 \mathrm{M}$ website views per year

At BMC, research is always in progress.

Learn more biomedcentral.com/submissions 